www.jmscr.igmpublication.org

Impact Factor 5.84

Index Copernicus Value: 71.58

ISSN (e)-2347-176x ISSN (p) 2455-0450

crossref DOI: _https://dx.doi.org/10.18535/jmscr/v6i1.37

Journal Of Medical Science And Clinical Research

IGM Publication

An Official Publication of IGM Publication

\title{
A Clinico-Profile Study of Chronic Obstructive Lung Disease at a Tertiary Care Hospital in Tamilnadu
}

\author{
Authors \\ Sasikumar Perumal ${ }^{1}$, Sureshkumar Krishnan ${ }^{2}$, Ravikumar Padmanaban $^{3}$, \\ Arivumani Meganthan ${ }^{4}$, Karthick Kuppan ${ }^{5}$, Shankar Radhakrishnan ${ }^{6}$ \\ ${ }^{1,2,3,4,5}$ Assistant Professor, Dept of Internal Medicine, Government Medical College, Dharmapuri, (TN) \\ ${ }^{6}$ Associate Professor, Department of Preventive Medicine, VMKVMCH, Salem \\ Email: shnkr_radhakrishnan@yahoo.com \\ Corresponding Author
}

Sasikumar Perumal

Assistant Professor, Department of Internal Medicine, Government Medical College, Dharmapuri, (TN)

Email:drsasmd@gmail.com

\begin{abstract}
Background: Chronic obstructive pulmonary disease (COPD) is considered as a major public health problem in the current era. In India COPD found to be more common in the general population and it is one of the major cause of morbidity and mortality. The chronic airflow limitation is caused by mixture of small airways disease (obstructive bronchiolitis) and parenchymal destruction (emphysema).

Aim: To study and analyse the lung function test, ECG, chest X-ray and haematological parameters among the patients with COPD.

Methodology: A cross-sectional observational study was conducted for a period of 6 months at Dharmapuri Medical college Hospital. Patients with age 40 and above a known case or a newly diagnosed case of COPD and who gave the consent were included in the study. A total of 150 patients with COPD were included in our study. History related to alcohol intake and any other exposure to smoke and dust and any other addiction was noted. A complete general physical examination and systemic examination including a thorough respiratory system examination was conducted. Pre and post bronchodilatory spirometry was performed in all patients as per the ATS guidelines for spirometry.

Results: The X-ray findings for 33.3\% of the patients showed features suggestive of chronic bronchitis and for $21 \%$ of the patients had features of both chronic bronchitis and emphysema. The most common abnormal ECG finding among the study subjects was right ventricular hypertrophy followed by right atrial enlargement. In the haematological examination we found $31 \%$ had mild anemia, $14.5 \%$ had moderate and $2.6 \%$ had severe anemia. Based on the spirometry readings we found $52 \%$ of the patients had moderate COPD, $40.6 \%$ had severe COPD and $7.3 \%$ had very severe COPD. A strong positive correlation was seen between the cigarette pack years and the severity of COPD $(r=0.873)$, which proves that as the number of cigarette pack years increases the severity of COPD increases.

Conclusion: Patients with dyspnoea and cough should be thoroughly investigated for COPD along with cardiac evaluation with ECG and ECHO so that early intervention can be made to reduce the disease burden both in terms of morbidity and mortality.

Keywords: COPD, spirometry, ECG, haemoglobin, cigarette pack years.
\end{abstract}




\section{Introduction}

Chronic obstructive pulmonary disease (COPD) is considered as a major public health problem in the current era. In India COPD found to be more common in the general population and it is one of the major cause of morbidity and mortality. It is estimated that it will be the third leading cause of death by 2030. ${ }^{1}$ GOLD (Global Initiative for chronic Obstructive Lung Disease) defines COPD as 'a preventable and treatable disease with some significant extrapulmonary effects that may contribute to the severity in individual patients. Its pulmonary component is characterized by airflow limitation that is not fully reversible. The airflow limitation is usually progressive and associated with an abnormal inflammatory response of the lung to noxious particles or gases. A clinical diagnosis confirmed with spirometry (FEV1/FVC <0.70) should be considered in patients with dyspnea, chronic cough, and sputum production and history of exposures to risk factors. Traditionally COPD management was based on spirometry values and until recently the decision on therapeutic options was based mainly on which GOLD stage patients were classified as well as whether they had frequent annual exacerbations or not. ${ }^{2}$

According to the ministry of health and family welfare, India has 17 million persons living with chronic obstructive pulmonary disease number that is estimated to rise to 22 million by 2016; it's good to remember here that there was time when COPD was relatively an unknown term. ${ }^{3}$ One Indian study has reported that nearly 12 million Indians are affected by COPD, above the age of 30 , with a prevalence rate of $5 \%$ among male and $3 \%$ in women. ${ }^{4}$ All available data indicate that COPD is often under diagnosed, detected very late and/or misdiagnosed as asthma.

The chronic airflow limitation is caused by mixture of small airways disease (obstructive bronchiolitis) and parenchymal destruction (emphysema). These changes do not always occur together, but evolve at different rates over time. Chronic respiratory symptoms may precede the development of airflow limitation and may exist in individuals with normal spirometry. ${ }^{5,6}$ Across the world, tobacco smoking is the commonest risk factor for COPD. ${ }^{4}$ Both active and passive smoking account for respiratory symptoms. Occupational exposure to organic and inorganic dusts, chemical agents and fumes, are other risk factors for COPD. ${ }^{7,8}$ There is growing evidence that indoor air pollution from biomass cooking and heating in poorly ventilated dwellings is an important risk factor for COPD. The role of outdoor air pollution is unclear. ${ }^{9,10}$

The disease often presents with shortness of breath, increased sputum production and significant reduction of exercise tolerance. Cough is often the first symptom of COPD. Cough may be productive or unproductive. ${ }^{11}$ Cough with sputum production is present in $30 \%$ of patients. These symptoms may vary from day to day. Wheezing and chest tightness are other accompanying symptoms. Fatigue, weight loss and anorexia are common problems in patients with severe and very severe COPD. ${ }^{12}$ Ankle swelling may be an indicator of corpulmonale. The most important and common co-morbidity associated with COPD is cardiovascular disease. Other complications that are under diagnosed are osteoporosis, depression etc. COPD can also be associated with lung cancer and can be a major contributor to death in COPD patients.

As of today studies related to COPD were very few in India and so the present study was conducted to see the various clinical manifestations supported by lung function tests, cardiac assessment and certain hemotological parameters.

\section{Aim}

To study and analyse the lung function test, ECG, chest X-ray and haematological parameters among the patients with COPD.

\section{Methodology}

A cross-sectional observational study was conducted for a period of 6 months at Dharmapuri Medical college Hospital. The study was started 
after getting approval from the institutional ethical committee and the informed consent was obtained from all the study participants. Patients with age 40 and above a known case or a newly diagnosed case of COPD and who gave the consent were included in the study. A total of 150 patients with COPD were included in our study. A known case of tuberculosis, bronchiectasis, patients with sleep apnoea syndrome were excluded from the study.

Patient's name, age, sex, race, marital status, occupation and address were recorded. Symptoms such as dyspnoea, cough, fever, sputum, hemoptysis, chest pain, and loss of appetite, loss of weight, dysphasia, and night sweat were recorded and analyzed. Past history of antitubercular treatment, any associated co-morbidity, any medication patient taking, patient any hormonal therapy, any congenital or acquired heart diseases, any history of allergy and any history of surgery in past.

Personnel history related to smoking habits was taken as per pack years. The pack-year is a unit for measuring the amount a person has smoked over a long period of time. It is calculated by multiplying the number of packs of cigarettes smoked per day by the number of years the person has smoked. History related to alcohol intake and any other exposure to smoke and dust and any other addiction was noted. Family history of infertility, diabetes, systemic hypertension and heart diseases was taken. Menstrual history had been taken of age of menarche, last menstrual period, and age of menopause. A complete general physical examination and systemic examination including a thorough respiratory system examination was conducted. Pre and post bronchodilatory spirometry was performed in all patients as per the ATS guidelines for spirometry. Persistent airflow limitation was defined by FEV1/FVC $<70 \%$ and an FEV1 post bronchodilator reversibility of less $200 \mathrm{ml}$ and $12 \%$. We classified the airflow obstruction as mild- Gold 1 (FEV1>80\%), moderate- Gold 2 (FEV1=50-80\%), severe Gold 3 (FEV1=30-50\%) and very severe Gold 4 (FEV1<30\%) based on post bronchodilator FEV1. All patients had underwent an electrocardiogram (ECG) recording and a chest X-ray was taken and it was interpreted by a radiologist. A complete hemogram was also done for all the patients. All the data were entered and analysed by using SPSS version 20. Mean and standard deviation was calculated for all the parametric variables, chi-square test and spearman's correlation test was used to assess the association between the non-parametric variables.

\section{Results}

The age and sex wise distribution of the study population was shown in table 1. It is seen from the table that majority of the study subjects were males and most of them were in the age group of between $50-70$ years and the mean age was 55.6 years among males and 52.8 years among females. The duration of the presenting illness varied between $2-20$ years with a mean duration of 5-6 years (table 2). The risk factor exposure among the study subject had shown that cigarette smoking or tobacco chewing was the most common factor among the study subjects particularly among males, whereas among females indoor air pollution was found to be the most common cause (table 3).

Among the smokers more than $50 \%$ of the study subjects had the history of more than 30 pack years, with a minimum of 10 pack years and the maximum of 45 pack years (table 4). Based on the presenting symptoms all our study subjects had the complaint of dyspnoea and cough followed by expectoration and few patients had wheeze and fever (table 5). The X-ray findings for $33.3 \%$ of the patients showed features suggestive of chronic bronchitis and for $21 \%$ of the patients had features of both chronic bronchitis and emphysema (table $6)$.

The most common abnormal ECG finding among the study subjects was right ventricular hypertrophy followed by right atrial enlargement and $10 \%$ of the patients had features of both RAE and RVH and for $56 \%$ of the patients ECG was found to be normal (table 7). In the hemotogical 
examination haemoglobin and haematocrit were measured and based on the values the grading of anemia was done and we found that $50 \%$ of our study population had normal haemoglobin, $31 \%$ had mild anemia, $14.5 \%$ had moderate and $2.6 \%$ had severe anemia (table 8).

We classified the airflow obstruction as mildGold 1 (FEV1>80\%), moderate- Gold 2 (FEV1=50-80\%), severe Gold 3 (FEV1=30-50\%) and very severe Gold 4 (FEV1<30\%) based on post bronchodilator FEV1. In our study subjects we found $52 \%$ of the patients had moderate COPD, 40.6\% had severe COPD and 7.3\% had very severe COPD (table 9). We found a strong positive correlation between the cigarette pack years and the severity of COPD $(r=0.873)$, which proves that as the number of cigarette pack years increases the severity of COPD increases.

Table 1: Age and sex wise distribution of the study population

\begin{tabular}{|l|c|c|c|}
\hline Age group & Males & Females & Total \\
\hline $40-50$ & $28(20.5 \%)$ & 0 & $28(18.6 \%)$ \\
\hline $51-60$ & $31(22.7 \%)$ & $6(42.8 \%)$ & $37(24.6 \%)$ \\
\hline $61-70$ & $51(37.5 \%)$ & $3(21.4 \%)$ & $54(36 \%)$ \\
\hline $71-80$ & $23(16.9 \%)$ & $4(28.5 \%)$ & $27(18 \%)$ \\
\hline$>80$ & $3(2.2 \%)$ & $1(7.1 \%)$ & $4(2.6 \%)$ \\
\hline Total & $136(100 \%)$ & $14(100 \%)$ & $150(100 \%)$ \\
\hline Mean \pm SD & $55.6 \pm 6.4$ & $52.8 \pm 7.1$ & $54.78 \pm 6.8$ \\
\hline
\end{tabular}

Table 2: Distribution of the study population based on the duration of illness

\begin{tabular}{|l|c|c|c|}
\hline Duration of illness & Males & Females & Total \\
\hline $2-5$ years & $54(39.7 \%)$ & $5(35.7 \%)$ & $59(39.3 \%)$ \\
\hline $6-10$ years & $45(33 \%)$ & $7(50 \%)$ & $52(34.6 \%)$ \\
\hline $11-15$ years & $29(21.3 \%)$ & $2(14.2 \%)$ & $31(20.6 \%)$ \\
\hline $16-20$ years & $8(5.8 \%)$ & 0 & $8(5.3 \%)$ \\
\hline Total & $136(100 \%)$ & $14(100 \%)$ & $150(100 \%)$ \\
\hline Mean \pm SD & $5.8 \pm 3.4$ & $5.2 \pm 4.1$ & \\
\hline
\end{tabular}

Table 3: distribution of the study population based on the risk factor exposure

\begin{tabular}{|l|c|c|c|}
\hline Risk factor & Males & Females & Total \\
\hline Cigarette/tobacco smoking & $119(87.5 \%)$ & $4(28.5 \%)$ & $123(82 \%)$ \\
\hline Air pollution (biomass) & 0 & $8(57.1 \%)$ & $8(5.3 \%)$ \\
\hline Occupation (cotton mill worker) & $17(12.5 \%)$ & $2(14.2 \%)$ & $19(12.6 \%)$ \\
\hline Total & $136(100 \%)$ & $14(100 \%)$ & $150(100 \%)$ \\
\hline
\end{tabular}

Table 4: Cigarette pack years among smokers in the study population

\begin{tabular}{|l|c|c|c|}
\hline Cigarette pack years & Males & Females & Total \\
\hline $10-19$ & $2(1.6 \%)$ & 0 & $2(1.6 \%)$ \\
\hline $20-29$ & $45(37.8 \%)$ & $2(50 \%)$ & $47(38.2 \%)$ \\
\hline $30-39$ & $62(52.1 \%)$ & $2(50 \%)$ & $64(52 \%)$ \\
\hline 40 and above & $10(8.4 \%)$ & 0 & $10(8.1 \%)$ \\
\hline Total & $119(100 \%)$ & $4(100 \%)$ & $123(100 \%)$ \\
\hline
\end{tabular}

Table 5: Distribution of the study subjects based on their presenting symptoms

\begin{tabular}{|l|c|c|c|}
\hline Presenting symptoms & Males $(\mathrm{n}=136)$ & Females $(\mathrm{n}=14)$ & Total $(\mathrm{n}=150)$ \\
\hline Dyspnoea & $136(100 \%)$ & $14(100 \%)$ & $150(100 \%)$ \\
\hline Cough & $136(100 \%)$ & $14(100 \%)$ & $150(100 \%)$ \\
\hline Expectoration & $103(75.7 \%)$ & $10(71.4 \%)$ & $113(75.3 \%)$ \\
\hline Wheeze & $58(42.6 \%)$ & $9(64.2 \%)$ & $67(44.6 \%)$ \\
\hline Fever & $23(16.9 \%)$ & $1(7.1 \%)$ & $24(16 \%)$ \\
\hline
\end{tabular}


Table 6: Distribution of the study subjects based on the X-ray findings

\begin{tabular}{|l|c|c|c|}
\hline X-ray findings & Males & Females & Total \\
\hline Chronic bronchitis & $46(33.8 \%)$ & $4(28.5 \%)$ & $50(33.3 \%)$ \\
\hline Emphysema & $38(27.9 \%)$ & $2(14.2 \%)$ & $40(26.6 \%)$ \\
\hline Chronic bronchitis and emphysema & $29(21.3 \%)$ & $3(21.4 \%)$ & $32(21.3 \%)$ \\
\hline Normal & $23(16.9 \%)$ & $5(35.7 \%)$ & $28(18.6 \%)$ \\
\hline Total & $136(100 \%)$ & $14(100 \%)$ & $150(100 \%)$ \\
\hline
\end{tabular}

Table 7: Distribution of the study population based on their ECG findings

\begin{tabular}{|l|c|c|c|}
\hline ECG findings & Males & Females & Total \\
\hline P pulmonale (RAE) & $19(13.9 \%)$ & $2(14.2 \%)$ & $21(14 \%)$ \\
\hline Right ventricular hypertrophy(RVH) & $28(20.5 \%)$ & $1(5.2 \%)$ & $29(19.3 \%)$ \\
\hline RAE + RVH & $15(11 \%)$ & $1(5.2 \%)$ & $16(10.6 \%)$ \\
\hline Normal & $74(54.4 \%)$ & $10(71.4 \%)$ & $84(56 \%)$ \\
\hline Total & $136(100 \%)$ & $14(100 \%)$ & $150(100 \%)$ \\
\hline
\end{tabular}

Table 8: Distribution of the study subjects based on the severity of anaemia

\begin{tabular}{|l|c|c|c|}
\hline Anaemia & Males & Females & Total \\
\hline Normal $\mathrm{Hb}$ & $74(54.4 \%)$ & $3(21.4 \%)$ & $77(51.3 \%)$ \\
\hline Mild anemia & $42(30.8 \%)$ & $5(35.7 \%)$ & $47(31.3 \%)$ \\
\hline Moderate anemia & $18(13.2 \%)$ & $4(28.5 \%)$ & $22(14.6 \%)$ \\
\hline Severe anemia & $2(1.4 \%)$ & $2(14.2 \%)$ & $4(2.6 \%)$ \\
\hline Total & $136(100 \%)$ & $14(100 \%)$ & $150(100 \%)$ \\
\hline
\end{tabular}

Table 9: Distribution of the study subjects based on the severity of COPD measured by spirometric values

\begin{tabular}{|l|c|c|c|}
\hline Grading of COPD & Males & Females & Total \\
\hline Mild & 0 & 0 & 0 \\
\hline Moderate & $74(54.4 \%)$ & $4(28.5 \%)$ & $78(52 \%)$ \\
\hline Severe & $51(37.5 \%)$ & $10(71.4 \%)$ & $61(40.6 \%)$ \\
\hline Very severe & $11(8 \%)$ & 0 & $11(7.3 \%)$ \\
\hline Total & $136(100 \%)$ & $14(100 \%)$ & $150(100 \%)$ \\
\hline
\end{tabular}

Table 10: Correlation between the cigarette pack years and severity of COPD.

\begin{tabular}{|l|c|c|c|c|}
\hline \multirow{2}{*}{ Cigarette pack years $(\mathrm{n}=123)$} & \multicolumn{3}{|c|}{ Severity of COPD } & \multirow{2}{*}{ R value } \\
\cline { 2 - 4 } & Moderate & Severe & Very severe & \multirow{2}{*}{0.873} \\
\hline $10-19(\mathrm{n}=2)$ & $2(100 \%)$ & 0 & 0 & \\
\hline $20-29(\mathrm{n}=47)$ & $47(100 \%)$ & 0 & 0 & \\
\hline $30-39(\mathrm{n}=64)$ & $2(3.1 \%)$ & $60(93.7 \%)$ & $2(3.1 \%)$ & \\
\hline 40 and above $(\mathrm{n}=10)$ & 0 & $1(10 \%)$ & $9(90 \%)$ & \\
\hline
\end{tabular}

$\mathrm{R}$ value derived by applying spearman's correlation test.

\section{Discussion}

COPD is a disease of increasing public health importance around the world. Estimates suggest that COPD will rise from sixth to third most common cause of death worldwide by 2020 . The present study highlights that the mean age of the COPD patients was 55 years and it is more common among males than the females. A similar type of observation was also shown in the study done by Deepali J etal. ${ }^{13}$ Another study done by Curkendall et al had shown that COPD is more common among older population and is highly prevalent in those aged more than 75 years. ${ }^{14}$ The study further quoted that only 9-10\% prevalence of COPD was found in adults aged less than forty years. This study also indicates that majority of the patients were males (90\%) with the mean age of 57.33 years. Another study in the Latin American Project showed COPD risk increases steeply with age, with the highest prevalence among those over 60 years. ${ }^{15}$

A systematic review and meta-analysis of the results done in 28 countries between 1990 and $2004,{ }^{16}$ and an additional study from Japan by Loveridge $\mathrm{B}$ etal stated that the prevalence of COPD was lower in non-smokers compared to 
smokers. ${ }^{17}$ A similar type of results was also seen in our study which had shown that $82 \%$ of our study subjects were smokers. The prevalence of tobacco smoking is increasing worldwide and is very strongly associated with COPD.

A large US population- based National Health and Nutrition Survey III which had examined 10,000 adults had estimated that the fraction of COPD attributable to workplace exposures was $19.9 \%{ }^{18}$ However in our study $12.6 \%$ of patients gave a positive history of workplace exposure. This could be due to the fact that there is not much awareness about workplace related hazards in our country. Similarly, in females, exposure to biomass fuel is high due to the cooking practices in our villages ${ }^{19}$ and our study had proven it as $5 \%$ of the study subjects particularly females had biomass exposure.

In our study almost all the patients had cough and dyspnoea as the major presenting complaint followed by expectoration and wheeze. $80 \%$ of the patients with dyspnoea had grade III to IV which is almost in par with the study done by Deepali J etal $^{13}$ in which $82 \%$ of the study subjects had dyspnoea of grade $3-4$ and in a study by N K Jain etal $38 \%$ of the study subjects had moderate to severe dyspnoea. ${ }^{20}$ The radiological findings of our patients had confirmed that chronic bronchitis followed by emphysema are the two most common COPD as most of the radiological features were showing moderate to severe airflow obstruction with a severe parenchymal damage and these findings were almost similar to the study done by Birring SS et $\mathrm{al}^{21}$ and Deepali $\mathrm{J}$ etal. $^{13}$

The present study shows that $44 \%$ of the patients had ECG abnormalities with features of either right atrial enlargement or right ventricular enlargement or a combination of both. In a study done by Agarwaletal ${ }^{22}$ ECG changes were present in $35.7 \%$ and $\mathrm{P}$ pulmonale was present in $35.7 \%$ patients of COPD. In a study by Chappell, ${ }^{23} \mathrm{P}$ pulmonale was found in $10 \%$ of COPD patients and right ventricular hypertrophy in $10 \%$. Ursa Bones et $\mathrm{al}^{24}$ found right ventricular hypertrophy in $17 \%$ patients, right axis deviation in $11 \%$, right bundle branch block in $8 \%$ patients and atrial fibrillation in $13 \%$ patients and in the study done by Deepali J etal $50 \%$ of the patients with COPD had ECG abnormality. ${ }^{13}$ In our study we had not further evaluated with echocardiography due to logistic constraints.

In the current study based on the FEV1 values we found $52 \%$ of the patients had moderate COPD, 40.6\% had severe COPD and $7.3 \%$ had very severe COPD and a similar type of results was also shown by Vithalnarayandhadke etal ${ }^{25}$ and Gupta etal. ${ }^{4}$ As smoking is the main cause of COPD, the smoking habit and no. of pack years had shown a significant positive correlation with the disease severity in COPD patients in the present study. The likelihood of developing COPD increases with the total smoke exposure. ${ }^{10}$

\section{Conclusion}

In the present study of 150 cases, COPD was predominantly seen in male patients, with a mean age of 55 years. Tobacco smoking was the commonest etiological factor followed by exposure to occupational dust and biomass fuel. Tobacco smoking was more common in males, while biomass fuel was more common in females. Clinical symptoms most commonly documented were dyspnoea, cough with or without expectoration, wheezing and fever. The ECG finding had shown that right atrial enlargement and right ventricular hypertrophy as the most common findings. The spirometry readings confirmed moderate COPD was more common followed by severe and very severe COPD among the study subjects. The smoking habit and the no.of pack years showed a significant positive correlation with the disease severity in COPD. Patients with dyspnoea and cough should be thoroughly investigated for COPD along with cardiac evaluation with ECG and ECHO so that early intervention can be made to reduce the disease burden both in terms of morbidity and mortality. 


\section{References}

1. Mathers CD, Loncar D. Updated projections of global mortality and burden of disease, 2002-2030: data sources, methods and results. Geneva; WHO 2005.

2. From the Global Strategy for the Diagnosis, Management and Prevention of COPD, Global Initiative for Chronic Obstructive Lung Disease (GOLD) 2011. Available from: http://www.goldcopd.org/. (Accessed January 2017).

3. Ministry of health and family welfare government of Indi http://mohfw.nic.in/WriteReadData/1892s/f ile16- 29724885.pdf. Accessed on Feb 2017.

4. Gupta D, Agarwal R, Agarwal AN. Guidelines for Diagnosis and Management of Chronic Obstructive Pulmonary Disease: Joint Recommendations of Indian Chest Society and National College of Chest Physicians (India). Indian J Chest Dis Allied Sci. 2014;56:5-54.

5. Woodruff PG, Barr RG, Bleecker E. Clinical Significance of symptoms in smokers with preserved pulmonary function. N Engl J Med. 2016;374(19): 1811-21.

6. Regan EA, Lynch DA, Curran- Everett D. Clinical and radiological disease in smokers with normal spirometry. JAMA Intern Med. 2015;175(9):1539-49.

7. Kohansal R, Martinez- Camblor P, Agusti A, Buist AS, Mannino DM, Soriano JB. The natural history of chronic airflow obstruction revisited: an analysis of the Framingham offspring cohort. Am J RespirCrit Care Med. 2009;180(1):3-10.

8. Eisner MD, Anthonisen N, Coultas T. An official american thoracic society public policy statement: novel risk factors and the global burden of chronic obstructive pulmonary disease. Am J RespirCrit Care Med. 2010;182(5):693-718.
9. Paulin LM, Diette GB, Blanc PD. Occupational exposures are associated with worse morbidity in patients with chronic obstructive pulmonary disease. Am J RespirCrit Care Med. 2015;191 (5):557-65.

10. Assad NA, Balmes J, Mehta S, Cheema U, Sood A. Chronic obstructive pulmonary disease secondary to household air pollution. Semin Resp Crit Care Med. 2015;36(3):408-21.

11. Cho SH, Lin HC, Ghoshal AG. Respiratory disease in Asia- Pacific region: cough as the key symptom. Allergy Asthma Proc. 2016;37(2):131-40.

12. Von Haehling S, Anker SD. Cachexia as a major underestimated and unmet medical need: facts and numbers. J Cachexia Sarcopenia Muscle. 2010;1(1):1-5.

13. Deepali J. Kamdar, Dharmesh Kumar Patel.A study of the clinical profile of 50 patients of COPD with correlation between clinical, radiological and spirometric evaluation. International Journal of Research in Medical Sciences. May 2017.Vol 5. Issue 5.

14. Curkendall SM, DeLuise C, Jones JK, Lanes S, Stang MR, Goehring E Jr, et al. Cardiovascular disease in patients with chronic obstructive pulmonary disease, Saskatchewan Canada cardiovascular disease in COPD patients. Ann Epidemiol. 2006;16:63-70.

15. Celli BR, Rassulo J, Make BJ. Dyssynchronous breathing during arm but not leg exercise in patients. with chronic airflow obstruction. N Engl J Med. 1986;314(23):1485-90.

16. Curkendall SM, DeLuise C, Jones JK, Lanes S, Stang MR, Goehring E Jr, et al. Cardiovascular disease in patients with chronic obstructive pulmonary disease, Saskatchewan Canada cardiovascular disease in COPD patients. Ann Epidemiol. 2006;16:63-70. 
17. Loveridge B, West P, Kryger MH, Anthonisen NR. Alteration in breathing pattern with progression of chronic obstructive pulmonary disease. Am Rev Respir Dis. 1986;134(5):930-4.

18. Hnizdo E, Sullivan PA, Bang KM, Wagner G. Association between chronic obstructive pulmonary disease and employment by industry and occupation in the US population: a study of data from the Third National Health and Nutrition Examination Survey. Am J Epidemiol. 2002;156(8):738-46.

19. Ezzati M. Indoor air pollution and health in developing countries. Lancet. 2005;366 (9480):104-6.

20. Jain NK, Thakkar MS, Jain N, Rohan KA, Sharma M. Chronic obstructive pulmonary disease. Does gender really matter? Lung India. 2011;28(4):258-62.

21. Birring SS, Brightling CE, Bradding $\mathrm{P}$, Entwisle JJ, Vara DD, Grigg J, et al. Clinical, radiologic and induced sputum features of chronic obstructive pulmonary disease in non- smokers. A descriptive study. Am J RespirCrit Care Med. 2002;166:1078-83.

22. Agarwal, R. L., Kumar, D., Gurpreet, Agarwal, D. K. and Chabra, G. S. 2008. Diagnostic Values of Electrocardiogram in Chronic Obstructive PulmonaryDisease (COPD). Lung India, 25:78-81.

23. Chappell AG. 1966. The Electrocardiogram in Chronic Bronchitis and Emphysema. Br Heart J., 28:517-22.

24. Ursa Bones, Miha Zabret, Irena Sarc, Mitja Kosnik, Stanislav Suskovic, and Mitja Lainscak. 2011. Electrocardiogram Analysis and Survival of Patients with Chronic Obstructive Pulmonary Disease. Chest, 140:575A.
25. Vithalnarayandhadke, Shubhangi Vithaldhadke, Nikhil Raut. Clinical profile in chronic obstructive pulmonary disease patients and their Evaluation with spirometry and 2D echo. International Journal of Current Research. Feb 2015. Vol. 7, Issue, 02, pp.12480-12488. 